\title{
Expatriates as Catalysts: What and how Vietnamese locals learn from self- initiated expatriates
}

Fee, A. and Gray, S.J. (2020), "Expatriates as catalysts: what and how Vietnamese locals learn from self-initiated expatriates", Cross Cultural \& Strategic Management, ahead-of-print. https://doi.org/10.1108/CCSM-08-2019-0145

\begin{abstract}
- Purpose: In an era when expatriates are increasingly used as strategic conduits for developing capabilities in local business units, we identify what and how host-country nationals in a developing economy learn from self-initiated expatriates whose assignments focus on organizational capacity development objectives.

- Design/methodology/approach: Semi-structured interviews with 23 Vietnamese hostcountry nationals rendered a sample of 138 learning episodes for qualitative content analysis. Respondents were employed in Vietnamese government and non-government organizations and worked closely with multiple self-initiated expatriates in a variety of professional contexts.

- Findings: Host-country nationals develop a broad array of primarily 'soft' capabilities. This learning is typically informal and vicarious in nature. While learning tends to arise incidentally through day-to-day activities, host-country nationals facilitate this by structuring their formal and informal interactions with expatriates to maximize their learning potential.

- Research limitations/implications: While the study's exploratory design and specific context limit the transferability of our results, analysis of a sample of specific learning episodes allowed us to map 'hotspots' of particular activities and contexts in which certain learning outcomes transpired.

- Practical implications: Our results put into sharp focus the overlooked roles of expatriates as models (to be observed), mentors (to be consulted), and collaborators (to be partnered with) who can catalyse valued learning opportunities for local colleagues.

- Originality/value: We provide a comprehensive account of the nature and extent of informal learning that host-country nationals accumulate during interactions with expatriates, and so contribute to a more nuanced understanding of the experiences of host-country nationals in international business.
\end{abstract}

Key words: informal learning, host-country nationals, self-initiated expatriates,

Vietnam, HCN learning, 'soft' capabilities

Acknowledgements: We thank Professor Yasunobu Okabe and Lucy Yang for important insight to our analysis for this article, as well as editor Leigh Anne Liu and the anonymous reviewers for their suggestions. 
In this study we examine the knowledge and skills passed on by self-initiated expatriates in capacity development roles in the Socialist Republic of Viet Nam ('Vietnam'), a developing economy, through the eyes of the host-country nationals (HCNs) with whom they work. We address the question: what and how do HCNs learn from their interactions with expatriates? The importance of this issue is reinforced by growing pressure on organizations to acquire, share and utilize knowledge and capabilities within and from outside the organization. Consistent with knowledge- and resource-based views of the firm (Grant, 1996), organizational efforts to use expatriates as conduits to introduce new ideas and skills across borders is increasingly recognized as important. This can be achieved either via multinationals deploying their staff internally (Hocking et al., 2007) or through local organizations recruiting expatriates from outside the organization (Arp et al., 2013; Shao and Al Ariss, 2020; Vaiman et al., 2015). Yet despite expatriates' contributions receiving attention from academia, the $\mathrm{HCN}$ side of the equation remains unexplored. Consequently, what and how HCNs learn from their interactions with expatriates is still largely unknown (van Bakel, 2019). Without a clear understanding of this, organizations' efforts to facilitate or measure this strategic development resource will remain unfulfilled.

Responding to this practical need, and to researchers' calls to break new empirical ground by mapping what and how people learn in under-studied contexts (e.g. Billett 2001; Manuti et al. 2015; Marsick et al. 2017), our research evaluated the experiences of Vietnamese HCNs working with expatriates. The expatriates were externally-recruited selfinitiated placements whose primary objective was to develop the Vietnamese host organizations' capabilities. Consequently, HCNs' learning was central to the expatriates' role. We anchor the research design in theoretical models of individual informal learning (Marsick and Watkins, 2001) that focus on discrete learning episodes attributable to HCNs' work with expatriates. Learning episodes are particular activities, interactions and other experiences 
(planned or incidental) that occur within a defined context and time period and that contribute to learning. As much as $70 \%$ of employees' developmental experiences arise informally, occurring naturally through everyday experiences rather than in training rooms (Enos et al., 2003; Skule, 2004). Because of the variable contexts in which they occur, informal learning episodes in the workplace are less predictable and can lead to outcomes much more diverse than those reported in institutionalized environments (Bell et al., 2009). Learning is sporadic, learner-directed and often deeply embedded in the work context, and so 'hard to separate from the work challenge that prompts it' (Marsick et al., 2017, p. 27). For this reason, the enabling and inhibiting features of learning experiences - not just the specific context in which the learning is triggered and the outcome that is enacted - are central to understanding the learning process.

To our knowledge, no studies have yet documented the breadth and pattern of learning experiences that HCNs draw from their intercultural interactions with expatriates. Our examination of this phenomenon enabled us to map prominent learning-rich activities and contexts - which we call 'learning hotspots' - that punctuate HCN-expatriate interactions. By revealing these learning hotspots, our study provides the first comprehensive empirical account of the nature and extent of learning that HCNs accumulate during expatriate assignments.

We present our paper in four parts, starting with the theoretical and empirical foundations guiding our research. We then summarize the research approach and report the outcomes of our investigations. We conclude by drawing out the study's theoretical and practical implications.

\section{LITERATURE REVIEW}

While there are many reasons for using expatriates, one of the most prominent is to improve local operations by developing the capabilities of HCN staff (Caligiuri and Bonache, 
2016). Used this way, expatriates are important conduits for expanding an organization's pool of valuable capabilities (Bonache and Brewster, 2001). This can be achieved by 'assigned' expatriates who are relocated within a multinational organization to transfer organizational knowledge from and to different business units, or by 'external' expatriates drawn from outside the organization for their specific expertise or experiences (Andresen et al., 2014), and to inject new knowledge, skills and ideas into the organization (Arp et al., 2013). This use is consistent with contemporary resource-based perspectives of internationally-exposed organizations, which emphasize the benefits of systemically sharing knowledge and expertise across an organization's breadth (Hocking et al., 2004). In this way, expatriates make strategic contributions by circulating knowledge and skills (Minbaeva and Michailova, 2004) and so are central to an organization's talent development template (Evans et al., 2011).

Our study focuses on what and how HCNs learn from their interactions with expatriate colleagues. 'Learning' is defined as all processes that lead to a relatively lasting change of capabilities which are not attributable to genetic-biological maturation (Illeris, 2002). 'Capabilities' comprise an individual's knowledge, understanding, worldview, skills and/or values (e.g. Illeris, 2003), and include 'hard' capabilities that relate directly to particular tasks associated with professional fields (domain-specific capabilities), as well as 'soft capabilities' not immediately associated with particular professions but which facilitate or enable performance, like communicating, managing relationships, leading, making decisions, motivating oneself, and working in teams (Robles, 2012). In defining soft capabilities in this way, our usage is close to the original conceptualization of the term (Whitmore, 1972a), which focused on distinguishing the skills of 'people operators' who possess ‘job related skills involving actions affecting primarily people and paper’ (Whitmore, 
1972b) from those of a 'machine operator.' ${ }^{\text {Th }}$ These capabilities are recognized as being simultaneously important across professional (and social) fields, and challenging to inculcate via formal education (Rubin and Dierdorff, 2009).

Studies of informal learning have grown to represent an influential body of literature that has drawn attention to learning through day-to-day activities (Evans et al., 2006) that can be either deliberate, such as self-directed study and structured mentoring, or it can be incidental (Eraut, 2004), an accidental by-product of other activities like learning from mistakes or problem-solving (Marsick and Watkins, 2001). Theories of informal learning in the workplace build on foundations laid by more generalized theories of adult learning that emphasize the social, opportunistic and problem-focused nature of the learning process (Bandura, 1977; Kolb, 1984; Lave and Wenger, 1991). The best known theoretical model in this realm is Marsick and Watkins' informal and incidental learning model (1990; 2001; 2018). While various iterations exist (see Marsick et al., 2017 for an overview), Marsick, Watkins and colleagues' (1990; 2001) model outlines 'a progression of meaning making' (Marsick and Watkins, 2001, p. 29) that is activated by a particular situation or disruption that occurs as individuals move throughout their work days. If the individuals' response to the context requires a new skill, insight or knowledge, the individual may initiate learning. Contextual factors influence all phases of the process, including the individual's willingness to learn, and the availability of appropriate resources like time, people from whom to learn, or available knowledge about the phenomenon. After a particular action is taken, an individual is able to assess its impact and digest any lessons from the experience. This new understanding then informs the individual's frame for future learning episodes. Work activities believed to be especially conducive to informal learning include activities that provide variety, novelty

\footnotetext{
${ }^{1}$ Whitman's usage, which focused on military leadership skills, drew on a definition of 'soft-skills' provided in 'CONARC Regulation on system engineering (CON Reg 350-100-1)' as: 'job related skills involving actions affecting primarily people and paper, e.g., inspecting troops, supervising office personnel, conducting studies, preparing ... reports' (Whitmore 1972, p. II4-II5)
} 
and challenge (Billett, 2001; Eraut, 2004; Fuller and Unwin, 2003; Marsick et al., 1999; van Gelderen et al., 2005), while opportunities to collaborate, consult, receive support or feedback, and even observe others have been shown to trigger learning in a range of settings (Cheetham and Chivers, 2001; Schürmann and Beausaert, 2016; Skule, 2004).

Focusing specifically on HCNs' learning, the most prominent strand of research relates to conscious efforts by organizations or expatriates to develop local offices (Riusala and Suutari, 2004), typically via transferring knowledge and skills as part of efforts to 'localize' a subsidiary (Leach, 1994). While some organizations appear to 'hope that localization (will) occur naturally' (Wong and Law, 1999, p. 30), organized activities like training, workshops, or structured mentoring programs (Law et al., 2004), revolving around domain-specific capabilities directly relevant to HCNs' technical roles (Riusala and Suutari, 2004), tend to be emphasized (Wong and Law, 1999). In these cases, it is the expatriate/s who dictate the form and process of 'learning'. By way of example, Hong and Snell (2008, p. 255) describe how the behaviors and identities of (Chinese) HCNs were manipulated by the dominant (Japanese) culture through 'enforced learning practices' (p. 264) and the expatriate managers' 'privileged access to knowledge resources and sense-giving power' (p. 255). Similarly, drawing on case studies of Thai automobile manufacturers, Petison and Johri (2008) propose a variety of expatriate roles (e.g. 'commander' or 'coach') based on the readiness of HCNs. A study of how subsidiaries in Vietnam and China acquired knowledge from the local context for the benefit of the (multinational) organization found formallystructured training and mentoring most efficacious, and that the extent (although not necessarily the type) of knowledge acquired could be facilitated by certain organizational policies, systems and infrastructure (V. Nguyen and F.L. Hong, 2013).

Besides these studies, researchers have hypothesized roles expected to be played by HCNs in instigating knowledge transfer by requesting particular types of knowledge (Shao 
and Al Ariss, 2020) or through taking on additional and/or unfamiliar work roles that provide opportunities to learn. These include socializing and supporting expatriates' adjustment (Toh et al., 2012) or linking expatriates to other HCNs via activities such as interpreting the language and/or culture, facilitating communication or organizational change, or brokering advice (Vance et al., 2009). To the extent that these roles would expose HCNs to new knowledge and/or opportunities to perform novel activities - for instance, as information boundary spanners (Vance et al., 2014) - they do hint at the types of learning opportunities that expatriates' presence may introduce. Supporting this, an empirical study of the communicative processes involved in expatriate-HCN knowledge sharing (Heizmann et al., 2018) found distinct roles played by expatriates and HCNs at different stages of the process that changed as the relationship developed. While not addressing HCN learning, per se, it reported HCNs performing various support behaviors that offer opportunities for learning through their unfamiliar or challenging nature, such as orienting expatriates to the local organization, mediating their contact with other HCNs, and applying expatriates' knowledge in local contexts. With similar sentiments, Van Bakel's (2019) review of studies of expatriate$\mathrm{HCN}$ interactions, while reiterating the dearth of $\mathrm{HCN}$-oriented studies, emphasized interaction frequency, depth, and breadth as important features of expatriate-HCN relationships, and thus presumably the learning possibilities involved therein.

While these studies hint that relatively normal work practices can be the impetus for HCNs' learning, no attempts have been made to identify specific activities that lead to HCNs' development in these situations, and what learning outcomes may arise from these. In aiming to address this oversight, we are heavily guided by prominent researchers (Billett, 2001; Eraut, 2004) who propose that understanding the patterns of workplace learning in particular contexts requires first 'identifying significant changes in understanding and capability and how these have come about' (Manuti et al., 2015, p. 6), and who emphasize the context in 
which learning occurs as a critical feature influencing every stage of the learning process (Marsick et al., 2017). In other words, understanding what and how informal workplace learning transpires, and the context in which it occurs, is a logical and necessary precursor to mapping the palette of HCNs' learning experiences. From this we pose three research questions to direct our empirical study; one focusing on HCNs' learning outcomes (RQ1) and two addressing important contextual features (RQ2-3)

RQ1: What do HCNs learn from their intercultural interactions and work experiences with expatriates (learning outcomes)?

RQ2: In what situations do HCN learning outcomes from expatriate interactions manifest themselves (learning context)?

RQ3: What contextual conditions enable or inhibit HCNs' learning from their interactions with expatriates (learning context)?

\section{RESEARCH DESIGN AND CONTEXT}

A mainly inductive process was designed to capture relatively unfiltered experiences of HCNs. The theoretical model we deployed (Marsick and Watkins, 1990; 2001; 2018), which focuses on specific learning episodes, lent itself to the use of a critical incident technique (Flanagan, 1954), a research approach which outlines a set of procedures that:

facilitates the investigation of significant occurrences (events, incidents, processes, or issues) identified by the respondents, the way they are managed, and the outcomes in terms of perceived effects (Chell, 1998, p. 56)

We applied this to a sample of retrospective learning episodes elicited during interviews with Vietnamese HCNs. All aspects of the study had pre-approval from a human research ethics committee on issues relating to consent, confidentiality and use.

\section{Sample}

Our sample of 23 HCNs were Vietnamese nationals working in 13 organizations active in three regions of Vietnam. First, with the assistance of Hanoi-based confederates, we 
identified 16 potential organizations with experience hosting expatriates who have organizational development objectives. All 16 organizations made abundant use of externallyrecruited, self-initiated expatriates. Contact with the organizations involved an initial Vietnamese-language information sheet followed by personal contact from the researchers. This resulted in 23 respondents from 13 organizations agreeing to participate; six international and four domestic NGOs, and three government agencies or State-owned enterprises. These organizations operated in a variety of sectors including development financing, vocational training, engineering, agriculture, labor relations, and disability services.

Our respondents, chosen for their ability to illuminate the phenomenon of $\mathrm{HCN}$ learning (Eisenhardt et al., 2016), comprised HCNs who had had sustained and regular contact with expatriates that were embedded in their organizations for medium- and long-term placements. For all HCNs this involved numerous daily interactions. Some respondents were designated counterparts for the full duration of some expatriate placements. All met our sampling criterion of at least 8 months of regular (i.e. daily) task-related interaction with multiple expatriates (ranging from two to eight), and thus had a breadth of sustained learning episodes upon which to report.

The expatriates with whom the HCNs worked were highly-skilled professionals employed on fixed-term contacts (most commonly 12 months duration) on local pay scales. Each had assignment objectives overtly centered on increasing the capacity of the host organization's systems and processes (e.g. strategy and policy development), and/or employees. Accordingly, important and explicit parts of the expatriates' roles included developing HCNs' professional capabilities (e.g. engineering, management, health services, law). The expatriates came from countries that included Australia, Canada, Finland, Germany, Japan, Malaysia, the United Kingdom, and the USA. From the descriptions provided by respondents, great variety existed in relation to the expatriates' professional backgrounds and 
roles. While it was evident that some expatriates had undertaken multiple assignments within the same organization previously (typically INGOs), in many cases, the expatriates' recruitment for this position was facilitated by organizations from outside the host organization (including some international agencies who place development volunteers) for a fixed 'one-off' tenure. In most (although not all) cases, the expatriates' professional backgrounds and hierarchical positions in the organization were similar to the HCNs with whom they worked. Importantly for our study, the unambiguous focus of expatriate placements on HCNs' learning meant that HCNs' professional development was an important feature of many interactions between respondents and their expatriate counterparts.

Table 1 identifies details of each HCN respondent including her/his identifying code, gender, and duration working with expatriates (mean $=33$ months). The table, which classifies respondents according to their professional role and type of employer, shows a mix of rural- and urban-based international NGOs (respondents \#01-10), domestic NGOs (\#11-18) and government agencies (\#19-23). Of the 23 respondents, six (26\%) had formal management responsibilities.

\section{TABLE 1}

\section{Data collection}

Interviews centered on respondents' own perceptions and interpretations of their experiences working with expatriates, including their identification of pertinent (to them) learning episodes. Specifically, using particular learning episodes as the study's unit of analysis, we asked respondents to identify learning outcomes (what was learned) and draw these together with the situations in which this learning took place, in terms of the social or experiential circumstances that triggered the learning, and the features that they felt helped or hindered this (learning context). This approach, used in previous research to unearth the 
learning outcomes and processes of managers (Akin, 1987) and expatriates (Fee and Gray, 2013) amongst others, enabled learning outcomes to be linked to particular workplace activities (Marsick and Watkins, 1990). Within this broad framework, interviews were facilitated to allow respondents to direct the flow of the discussion and raise, reiterate, or clarify points.

Most respondents spoke English as a non-native language and only five requested (and used) language translators. Interviews were digitally recorded and transcribed, yielding over 130,000 words for analysis (mean $=5856$ words). To be faithful to the original interviews and to recognize the multiple forms of global English in international business, extracts are reported verbatim as described by respondents.

\section{Data analysis}

The data coding process involved two experienced and trained researchers familiar with the transcripts and research objectives working in unison (first author and research assistant), with coding diaries forming the basis of ongoing face-to-face discussions. Initially, an extensive qualitative database of 138 learning episodes was extracted from the transcripts. For each, four descriptive codes (learning outcome/s, learning context, enablers, inhibitors) were articulated and cross-referenced to the source (respondent's code) and learning incident (numeric code). Within this framework and consistent with Marsick and Watkins' (2001) theory, learning outcomes were defined as respondents' reported learning or change that emerged from the learning episode, while the learning context was the activity or situation in which the respondent was participating when the learning took place. These data sets were then thematically coded in two stages. Initial nodes were developed from repeated verbatim phrases and words of respondents that were thematically linked. We then drew on a priori themes when abstracting these to higher-order categories. This resulted in five categories of 'learning outcomes' that were generally consistent with earlier typologies of informal and/or 
expatriate learning (Eraut, 2004; Fee and Gray, 2011) and so these categories, and their defining features, were used relatively unadulterated. A similar process with 'learning contexts' also matched well with existing theoretical models explaining formal and informal learning (see, for instance, Merriam et al., 2007), albeit with one notable addition; 'adjusting', defined as HCNs adjusting to the different work or communication style, or to new roles they were required to take on, as a result of the expatriates' presence. This led to the development of a coding template for both learning outcome and learning context that was used to re-code the full data set. In developing this, both researchers discussed coding iterations, data labels and category descriptions, and ultimately 'endorsed' a final coding template that guided the data analysis, a summarized version of which is at Table 2.

\section{TABLE 2}

Both data coders then used the coding template independently to code a sample of 20 learning episodes (14\%), before comparing and resolving discrepant data strips (three learning episodes representing $7 \%$ of coded materials). The lead author coded the remaining 118 learning episodes. Descriptions of learning enablers and inhibitors were cross-referenced to learning outcomes/contexts as a means of isolating features associated with particular types of episodes or respondents. Analysis involved reviewing the frequency with which enablers/inhibitors were associated with specific outcomes/contexts, a process led by the first author with support from the research assistant, and in discussions with other trained researchers familiar with the data set. In many cases enablers/inhibitors relating to a common theme were paired; for instance, the node that was eventually labelled 'strong and trusting relationship' was the most commonly identified enabler of learning, while its absence was identified regularly as an inhibitor (i.e. lack of trust). Overwhelmingly, descriptions of enablers or inhibitors covered multiple outcomes or addressed multiple contexts, with just a 
few relating to specific isolated episodes. For this reason, we report cross-cutting themes emerging from this analysis, and address relationships with particular learning outcomes and contexts where relevant.

\section{Research context}

Like its economy, Vietnam's culture is diverse and dynamic (Meyer et al., 2006) but shares several characteristics with other Confucian-influenced countries in the Asia-Pacific region, including orientations towards collectivism and hierarchy (Hofstede, 2010). Consequently, it has been proposed that Vietnamese organizations can be characterized by status-based respect and deference, indirect communication, reluctance to voice disagreement or ideas, and strong commitments to in-group membership (Meyer et al., 2006; Napier and Haong, 2013). Like many developing countries, a high value is placed on education and learning (Napier and Haong, 2013), and while Vietnamese organizations are often hampered by limited expertise and technology (Euromonitor International, 2018b) and by restrictions arising from the Government's central planning model (Euromonitor International, 2018a; Zhu and Purnell, 2006), some organizations have begun adopting Western-influenced human resource practices associated with staff training and recruitment (Zhu et al., 2008). We return to consider the influence of these features on the HCNs' learning in the Discussion section.

\section{FINDINGS}

\section{HCNs' learning outcomes and contexts (RQ1-2)}

All respondents were able to identify multiple prominent learning episodes (outcome and context) that they attributed to their experiences working with expatriates (mean $=6$ per respondent), allowing us to create a matrix linking 'learning contexts' and 'learning outcomes' for the sample learning episodes $(n=138)$. The two panels of Table 3 show the frequency that each learning outcome was reported (left hand columns) and the workplace 
context in which these outcomes occurred (top row). It also shows the percentage of the total sample of respondents reporting each learning outcome (column 2, Panel I).

TABLE 3 (PANELS I and II)

Several patterns are apparent in Table 3. Looking first at the learning outcomes, labelled 1-5 in the left hand column, while all respondents reported developing domainspecific capabilities relating to their profession (35/138 learning episodes, or $25 \%$ of all learning outcomes), most learning outcomes can be classified as highly personal or interpersonal 'soft' capabilities (Whitmore, 1972b). An executive from an international training center (\#20) described the sentiment of many respondents' learning experiences in the following observation:

I learn so much skills and knowledge from (expatriates') general activities like communication skill, planning skill or negotiation skill, many skills that are not items of the project activity but I can learn from them

The largest of the categories of soft capabilities was labelled 'personal development' (Table 3, 1.1-1.7; 41/138 learning episodes representing 30\% of all learning outcomes). This category included 'changed outlook' (Table 3, 1.1; 13 learning episodes) - for which HCNs emphasized viewing their profession, work or organization in new ways, including 'the view from a different angle' (respondent \#02), 'more strategic' (\#04), 'more systematic or logical' (\#08), or 'more open-minded' (\#22) - as well as the learning outcomes 'openness to different points of view' (Table 3, 1.2; 9 learning episodes) and 'overall self-confidence' (Table 3, 1.3; 7 learning episodes).

Other conspicuous categories of learning outcomes that comprised soft capabilities include 'role performance and management capabilities' (Table 3, 3.1-3.3; 27/138, 20\%), most commonly 'professionalism in work performance' (Table 3, 3.1; 15 learning episodes), 
where HCNs emphasized features like improving their work ethic, efficiency or approaches ('I think we learn how to use (our skills), we (are) more efficient in terms of the personal skills, and even in the (technical) skills we think more logically or work more professionally', \#12), and 'communication capabilities' (Table 3, 4.1-4.5; 27/138, 20\%), most of which related to improved English language skills (Table 3, 4.1-4.2; 13 learning episodes), but which also included other advanced communication skills like negotiating (\#14) or listening, as the national coordinator of a HIV/AID prevention program (\#19) explained:

The international experts ... really listen to us, listen and then speak, normally they do not react, do not speak individually after we speak. They listen first and then perceive the idea and then speak. You see that's the thing I really want to learn and want to apply.

Although not evident in Table 3, the bulk of the learning outcomes reported were relatively portable, with only $7 \%(9 / 138)$ involving outcomes that could be termed 'firmspecific', like the organization's management of expatriates (\#01,\#06,\#09), strategic priorities of different business units (\#04, \#20), or awareness of cross-department politics (\#16, \#18).

In terms of learning contexts - labelled 6-11 in the top row of Table 3 - just 5\% (7/138) of learning episodes occurred during structured 'training' (Table 3, 11.1-11.3) and only $25 \%$ (34/138) during situations where learning was the primary objective; 'structured modelling' (Table 3, 6.2), 'consulting' (Table 3, 10.1-10.3) and 'training' (Table 3, 11.111.3). In contrast, $75 \%$ of learning episodes (104/138) described situations that were both informal and incidental, occurring as a by-product of expatriates' presence in the host organization rather than as a planned part of expatriates' (or HCNs') activities. While several involved direct interactions with expatriates - most conspicuously 'collaborating' (Table 3, 7.1-7.4; 26/138), 'consulting' (Table 3, 10.1-10.3; 21/138) and 'discussing' (Table 3, 9.1-9.3; 19/138) - the largest single category came from HCNs observing expatriates performing their 
work ('observing', 38/138; Table 3, 6.1-6.2), which was a prominent contributor to HCNs' 'role performance and management capabilities' (Table 3, at the intersection of 3.1-3.3 and 6.1-6.2; equating to $15 / 27$ or $56 \%$ of the learning outcomes in this category), 'personal development' (Table 3, 1.1-1.7 and 6.1-6.2; 8/41, 20\%), and 'domain-specific capabilities' (Table 3, 2.1-2.4 and 6.1-6.2; 8/35, 23\%; e.g. 'I can see their working style ... I can see that she works very hard and I can really appreciate what she did', \#19). Our data also indicates that the extent and nature of learning by 'observing' was not related to HCNs' access to expatriates or communicative proficiency. Vicarious learning episodes were reported equally frequently by respondents who collaborated most regularly and intensively with expatriates as those whose interactions were less intensive; in other words, observational learning was not simply a result of HCNs being unable to access other contexts for learning. For these HCNs, it was a valuable learning strategy in its own right.

The opportunity to collaborate with expatriates (Table 3, 7.1-7.4; 'collaborating'), which accounted for $19 \%$ of all reported learning outcomes (26/138), was the activity that provided the most even range of learning outcomes across all five categories ('Ninety percent of the time we (learn from) working with them', \#14), mainly via concrete hands-on activities with strong experiential components such as jointly preparing funding proposals (\#01), making presentations (\#03), consulting stakeholders (\#02), or organizing events (\#15). One manager (\#04) with 60 months of experience working closely with seven different expatriates concluded that:

(Expatriates) should involve directly in the activities if you want to provide good advice and good coaching. We are working together on different things ... setting the strategic objective or implementing activities ... they should working together in specific activities.

Another prominent node was a previously unreported category of learning contexts that centered on HCNs' need to adjust their behaviors as a result of working with expatriates 
(Table 3, 8.1-8.3; 'adjusting', 27/138 learning episodes). Three types of adjustment were evident in the descriptions provided by respondents. 'Cultural differences' (Table 3, 8.1) came from HCNs recognizing and responding to differences between themselves and expatriates by reporting, for instance, more openness to different views (e.g. \#18), comfort working with people with different attitudes and expectations (\#06), or thinking in new ways (\#22):

Subtly we changed ... to work with people from different cultures ... there's no right or wrong when you're brainstorming, for example. We learn to adjust to those cultural differences (\#05).

The second form of adjusting, 'communicate differently' (Table 3, 8.2), came from HCNs' need to communicate with expatriates in ways that were unfamiliar, typically more directly or less formally (e.g. \#01, \#04,\#16). A country director of a disability services NGO explained that:

(We) learn from the experience or from the way that (the expatriate) may express herself; straightforward or voice your own opinion, your idea (\#05).

Pressure to adjust their communication style did create misunderstandings and confusion for HCNs ('You confused and worry about how to communicate with them', \#06), but also led several to embrace new modes of communication modelled by expatriates. As an example, the Vice Director of a government vocational training center (\#20) reported a personal transformation that was instigated by having to adjust to the communicative preferences of an expatriate counterpart:

During the time (the expatriate and I) work with each other I am very frank with people. I am frank to talk and to share my thoughts. And I think it is now my characteristic when I working with the other people. So when I say anything, my ideas, my thoughts, I think it is very open, we discuss everything. 
The third form of adjustment ('new role', Table 3, 8.3) involved HCNs performing work role/s that were new, unfamiliar and/or more challenging than their normal role. The most developmental of these was acting as a cultural, linguistic and social broker (e.g. \#02, \#09) connecting the expatriate to other HCNs both inside and outside the organization. Other new roles that required HCNs' adjustment included mediating communications or conflicts between the expatriate and other HCNs ('a middle man', \#01; 'whenever each side finds any difficulties I will be the person to resolve it', \#20), and helping expatriates adjust to the organization, office environment and culture (e.g. \#11, \#14, \#20).

\section{Enablers and inhibitors of HCN learning (RQ3)}

Respondents identified a multitude of features that enabled and inhibited their learning and which spanned individual characteristics (e.g. personal motivations or capabilities - \#07, \#11, $\# 19$ ), workplace conditions (e.g. time or funding available - \#09,\#13,\#21), and selection or preparation of expatriates or HCNs (e.g. \#19, \#20). Here we focus on the importance of three conditions that dominated responses across multiple categories of learning outcomes and contexts: (i) the quality of HCNs' relationship with expatriates, (ii) opportunities for non-task (e.g. social) contact with expatriates, and (iii) how HCNs' contact with expatriates was 'curated' to facilitate their learning. Each is discussed below.

(i) The quality of HCNs' relationship with expatriates: The most prominent enabling influence identified by HCNs was a 'strong and trusting relationship' between themselves and the expatriate. All 23 respondents raised this in relation to learning episodes, and variations on this covered all learning outcomes and all but one category of learning context ('training'). Two patterns were most noticeable. First, while associated with all learning outcomes, a trusting relationship with expatriates was identified most often with soft capabilities like 'personal development', 'role performance and management capabilities' and 'communication capabilities.' This was less common for learning episodes reporting domain- 
specific outcomes, where just 5/35 learning episodes (14\%) were associated with the quality of the expatriate-HCN relationship (relating to 'observing', 'collaborating' and 'consulting'). Second, the descriptions provided by respondents suggest that learning episodes enabled by trusting relationships tended to arise from sustained interactions and repeated modelling that occurred over time, rather than 'one-off' situations ('Once I got to know her I can learn much more', \#08; 'It increase time for sharing ... opportunities of sharing',\#12). In such activities, respondents described the learning as being a little like osmosis ('(I)t's something invisible but you can learn like that', \#12). This was especially true for vicarious learning episodes ('observing'). For instance, a trainee physiotherapist (\#09) who accompanied an expatriate treating numerous rural patients explained at length (and with precision) how, by observing the expatriates' regular interactions with patients, she improved her diagnostic and patient management skills, and outlined specific examples of how her treatments had subsequently improved. Similarly, a marketing professional (\#01) described her main learning in the following way:

Because we've worked closely together and we have done a lot of projects together, I learnt from him - (by) observation by example at the meeting - how he would deal with the investors; how he poses the questions and also in other activities not related (to marketing).

Some HCNs had difficulties explicating the relationships with expatriates that best enabled learning. Notwithstanding this, a number of respondents used quite similar terminology or examples to describe these. We summarize these as being fundamentally similar to 'informal mentor-protégé' relationships, characterized by two features. First, rather than peers or colleagues, expatriates who enabled HCNs' learning most effectively were perceived as specialist experts who could be regularly consulted, collaborated with, and observed. Among the most valued behaviors that expatriates shared were (what HCNs perceived as) exemplary professional standards. One respondent likened this to being 'in the 
middle of something totally best practice' compared with 'something very low style' used in Vietnam (\#09). Although none of the respondents reported working with expatriates who had roles that were formally designated as mentors, a common theme, summed up in the quote below, was:

It's more about a mentoring relationship. (The expatriate)'s not a manager who I need to report in every detail. Whenever I have a chance to give my own opinion and do things on my own (I do). But whenever I have difficulty, I can come up to him as expert to ask for opinion (\#01).

Second, as the preceding quote illustrates, in their relationships with expatriates HCNs appreciated the opportunity to consult experts who would not (formally) admonish their ideas or work but whom they could rely on for frank and informed feedback. A health services professional (\#12) described this as being 'comfortable - you create the good environment of working, so you feel good and you can do anything.' Several respondents shared examples where expatriates had 'protected' them by not disclosing mistakes and/or helping to correct (HCNs') errors (e.g. \#01,\#12, \#09). An administrative officer explained:

I'm feeling that we're not supervising what each other is doing. When we have something we don't know how to do it, and you just come to ask (expatriates), and maybe these will bring about ideas or initiatives ... I prefer the way that we do it by ourselves, and we just get support when we meet, but we can manage our job in a good manner (\#11).

From these descriptions, we infer that the best learning relationships with expatriates, as perceived by HCNs, were when expatriates were 'inside mentors' rather than 'external peers' or 'line supervisors'; that is, insiders possessing expertise but not formal power.

(ii) Opportunities for non-task (i.e. social) contact with expatriates: Another important feature of HCNs' learning, reported by respondents most often as an enabler, was being able to access opportunities for interactions with expatriates outside work situations. This non-task contact involved social exchanges in the office (e.g. coffee breaks, small talk) and outside 
work hours (e.g. lunch, drinks, dinners, site visits), as well as supporting expatriates with nonwork issues:

I helped him to buy a motorbike and introduced him how to travel in the city ... we build our relationship between us through some advice or other support system (\#14).

As respondents described them, these less structured interactions were important in helping HCNs develop the confidence they needed to communicate with expatriates in more task-focused situations, described most often as enabling a shared 'understanding' (e.g. 'If (expatriates) come to my house, they understand me, they can know my daily life and they can see how I live', \#20). Another HCN described how:

Things got closer very fast. After work (the expatriate) come to my place for dinner or we went out for dinner. We talk all the time, that's why it just take a few days (to become close) ... we hung out together and we shared information. We just feel like even (though) we come from different country but our expectation, our thought, our career, our thinking is similar. That's why the more we talk the more we get closer (\#09).

These interactions also served as platforms for learning in their own right. A sizable proportion of learning episodes involving observing, collaborating, adjusting, and discussing took place in non-work situations outside scheduled hours, a point stress by some respondents:

Social activity is very important ...when we're working with each other you have to stick to work ... when we do the social activities together, maybe we will discover many things about ourselves and about each other (\#11).

(I)t's not only through work ... daily conversation when you talk about your life and your (family) ... makes you more open to the difference (\#01).

(iii) How HCNs 'curated' contact with expatriates to facilitate learning: The third theme that we highlight from respondents' reports of enabling/inhibiting features was the conscious efforts that respondents and their employers took to facilitate informal learning. In 
other words, HCNs were acutely aware of the substantial informal learning opportunities that the expatriate placements presented, and they took steps to consciously increase their exposure to these. By way of example, a senior manager of a state-owned training center described how she and her $(\mathrm{HCN})$ colleagues:
Always try to take the best chance to talk with the (expatriate) to get the ideas, always talk to her, even invite her to the lunch, take her to the market or something. Not only in the office ... they always catch up with the (expatriate) and learn from (expatriate), (it is) very active from (the HCNs') side (\#22).

Several respondents reported rescheduling their work day in order to maximize 'contact time' with expatriates, from the hours they worked to when they took breaks or performed particular activities (e.g. \#09,\#11,\#14,\#15,\#22). Several linked their willingness for non-task contact with expatriates, reported earlier, with opportunities to learn (e.g. 'Yeah sure ... we learn from each other. I mean during our lunch time, for example, we share a lot of things (about) work or even out of work', \#13). One regional manager reported rejecting an alternative job offer specifically because of the learning opportunities he envisaged from working with an expatriate (\#17), while another used her close collaborations with an expatriate to instigate a change of career $(\# 09)$. This awareness of informal learning was evident in other ways during interviews. For instance, respondents were quick to identify a diverse array of ways that they learned; one director who had worked with multiple expatriate consultants and executive coaches summarized at the end of our interview: 'I get it from talking, watching, observing, and seeing ... from the work, from everything' (\#04).

As these examples allude to, HCNs demonstrated awareness of the types of situations that (they perceived) enabled the incidental learning opportunities that came from working with expatriates. We discuss this point further in the following final section. 


\section{DISCUSSION AND CONCLUSION}

This article reports an investigation into what and how host-country nationals learn from expatriates whose assignments focus on organizational development objectives in the context of government and non-government organizations in the developing country of Vietnam. Our analysis shows that the main learning outcomes that HCNs attain from working with self-initiated, externally-recruited expatriates are 'soft' capabilities rather than domainspecific expertise, and that this learning is overwhelmingly informal and very often vicarious, with planned training and structured feedback making only minor contributions to the portfolio of HCNs' learning experiences. We also find that, while HCNs' learning episodes mainly arise incidentally through interactions with expatriates, this is sometimes facilitated by HCNs intentionally positioning themselves and their work in situations that are perceived as conducive to this type of learning. This includes HCNs devoting non-work time to establishing trusting relationships with expatriates; a commitment HCNs saw as central to their informal learning.

The main theoretical insights arise from extending the application of informal learning to a new context (Eraut, 2004; Marsick et al., 2017) - namely, what and how HCNs learn from their interactions with expatriate colleagues. The results sit in contrast to existing assumptions about knowledge and skills transfer during international assignments that emphasize structured and planned strategies largely controlled by the firm and/or expatriate (Riusala and Suutari, 2004). Notably, we found a preponderance of HCNs' learning episodes relating to capabilities that were both 'soft' (Robles, 2012) and portable, and thus not tied to expatriates' or HCNs' specific technical expertise related to organizational settings. The objectives of the expatriates' assignments - explicitly to develop capacity within the organization - and the domain-specific focus of expatriates' consulting and training efforts (Table 3) suggest that the learning outcomes reported by respondents may have been additional or surplus outcomes that may not be fully recognized (or planned) by 
organizations, and which are yet to be addressed directly in literature pertaining to expatriates' roles in organizational development and/or localization (Law et al., 2009). While these unplanned learning outcomes may be attributable to the less predictable nature of all informal learning (Marsick and Watkins, 1990), our results draw attention to the high level of agency that HCNs assert in 'curating' their learning, both in terms of their intentionality towards their professional development and in terms of learning contexts that they deemed important. While not often acknowledged in the literature, informal learning contexts invest the learner with greater control than structured training, the focus of most localization literature, where an expert dictates curriculum, content and method. This agency appears most evident in the abundant use by HCNs of learning by observation, in spite of opportunities for other richer or more structured learning situations. While planned and incidental learning are commonly presented as mutually exclusive, we are struck by the similarity of respondents' behaviors to those described by Hunter $(2014 ; 2010)$ as intentional incidental learning, where professional workers are 'alert and receptive' (Hunter, 2014, p. 50) to opportunities to learn and intentionally place themselves:

in situations where learning might occur incidental to other activities ... the intention to learn is ever present, even when the activities are not primarily learning-focused (Hunter, 2010, p. 457)

Hunter's (2014, p. 50) study revealed actors who 'appreciated the ubiquitous nature of learning' and would regularly - indeed, continuously - 'observe, reflect, and file away as much as they can' in order to improve their work performance. In a similar way, the respondents' appreciation of the breadth of direct and vicarious learning that can come from their proximity to and contact with expatriates suggests active efforts to curate situations whereby learning may transpire, even when it is not the main purpose of the interaction. Our results therefore add empirical kindling to ways in which workers enact their roles as active learning agents. These results suggest a potentially fertile stream of research exists in trying to 
unpack the antecedents that attenuate this phenomenon, such as the ways in which an expatriates' (developmental) assignment might be framed to encourage intentional learning among their HCN counterparts.

A further contribution to the literature comes from the reported importance of trust in the expatriate-HCN relationship as an antecedent to and/or facilitator of informal learning, even in contexts where learning occurred vicariously. Trust between instructors and learners in formal adult education has long been recognized as necessary for effective learning, often framed from the perspective of the learners' psychological safety (Tennant, 1986). Similarly, mutual trust has been highlighted as important to sustaining structured mentor-protégé relationships (Guramatunhu-Mudiwa and Angel, 2017); however, to our knowledge no studies have examined the role of trust toward peers as an antecedent to incidental learning in workplace settings. Theoretically, trust may be seen as a route through which HCNs can evaluate the expatriates' competencies or overcome any pre-existing biases clouding their evaluations (Levin and Cross, 2004), and as such may be especially pertinent in intercultural informal learning situations (Johnson and Cullen, 2002). It may also explain the apparent benefit of repeated and sustained, rather than one-off, triggers for HCNs' learning, especially for the development of softer capabilities, the foundations for which may be 'more difficult (for expatriates) to impart' than technical (domain-specific) knowledge, and may 'require ongoing reinforcement' (Fryxell et al., 2004, p. 269-70; Szulanski, 1996). Also clear is that these patterns of learning (i.e. seeking repeated learning triggers from expatriate models who are closely observed) appear to be consistent with two features of HCNs' intercultural experiences. The first is the relatively smaller number of expatriates that HCNs are able to encounter (compared with expatriates' more wide-ranging exposure to HCNs in a foreign country), which may afford fewer opportunities for novel practices to trigger learning responses. The second is the high status that is sometimes attributed to expatriates (Manev 
and Stevenson, 2001). Both these features may heighten HCNs' attentional processes (Arp et al., 2013) and so encourage and facilitate vicarious learning (Bandura, 1977). Thus, while the role of trust may have been exacerbated by the study's content - involving Vietnamese respondents and workplaces in a country where in-group bonds and relationship-building are valued (Ralston et al., 1999) - future studies addressing the nature of trust and the ways in which it influences patterns of informal, incidental and intentional incidental learning - both outcomes and contexts - is likely to shed further light on the relationship that our study unveils.

The results also challenge extant literature that emphasizes expatriates as protagonists of learning within local offices; instead, our results suggest a more subtle and potentially more complex role for expatriates as catalysts of $\mathrm{HCN}$ learning through activities like unstructured role-modelling, mentoring, and collaborating. From these insights, we conclude that developing HCNs' capabilities may best be facilitated by selecting and deploying expatriates who are professional, competent, able to establish strong and trusting relationships, perform their role proficiently, and make themselves available to HCNs, rather than devoting energies to designing and/or delivering structured training. In other words, the most effective expatriates appear to be catalysts for, rather than protagonists of, HCNs' learning. ${ }^{2}$ Indeed, the types of learning episodes - both context and outcomes - that expatriates seem to activate in HCNs appear more similar to those reported in the literature on structured mentoring-protégé relationships (Hezlett, 2005) than those of expatriates' organizational development efforts reported earlier. It is feasible that less expatriate-centric modes of organizational development and/or localization may be received more favorably by,

\footnotetext{
2 The idea of expatriates as 'catalysts' emerged from discussions with Professor Yasunobu Okabe, Tohoku University, in 2018, and builds on ideas presented in: Hosono, A., Honda, S., Sato, M. \& Ono, M. (2011). Inside the Black Box of Capacity Development. In H. Kharas, K. Makino \& W. Jung (Eds.), Catalyzing development: A new vision for aid. Washington, DC: Brookings Institution Press.
} 
and more beneficial for, HCNs. Moreover, studies of formal mentoring relationships suggest that the HCNs' learning outcomes may not have been impeded by the relatively organic (i.e. informal) way that these relationships developed (Underhill, 2006), and that the expatriate mentors may have experienced comparable learning benefits (Liu et al., 2009), both phenomena worthy of further research.

On the issue of expatriate learning, when comparing HCNs' learning with the literature on expatriate learning, we find similarities and differences. Both appear to benefit from taking on unfamiliar and challenging roles, and from the informal learning and diverse outcomes that accumulate from this (Fee and Gray, 2013). Intriguingly, our findings produced evidence of the phenomenon of 'HCN adjustment' that arose from behavioral changes imposed by HCNs' interactions with expatriates. In some ways, respondents' descriptions echo aspects of the behavioral adjustments of expatriates, who - like the HCNs in this study adapt their work and communication practices to suit foreign colleagues (Froese et al., 2012) and frequently take on unfamiliar and challenging work roles (Lane et al., 2004). As well as providing some empirical support for the cross-cultural adjustment experienced by HCNs, our data also reinforce the potential for cultural adjustment pressure to instigate $\mathrm{HCNs}$ ' professional development. In this we draw parallels with explanations of cross-cultural adjustment as a social learning process that stems from the repeated observations and experiences sparked by immersion in new cultural environments (Black and Mendenhall, 1991). While cautious of generalizing too broadly, our findings suggest that the types of processes activated when expatriates are immersed in a foreign socio-cultural environment may be mirrored in some ways by HCNs engaging in immersive interactions with expatriates while remaining in their home culture. This, we propose, is a phenomenon ripe for future conceptual and empirical investigation. 
Beyond this, our study of HCNs' learning also extends understanding of the expatriate experience in several ways. The findings confirm the value of expatriates as mechanisms for sharing important capabilities throughout an organization via their important, and perhaps overlooked, function as models (to be observed), mentors (to be consulted), and collaborators (to be partnered with). While researchers are beginning to recognize that expatriates take on 'hidden' roles beyond their professional domain or job description (Petison and Johri, 2008), our data highlight characteristics of expatriation that are yet to be documented. Most obviously, the very high incidence of HCNs observing expatriates performing their work suggests that expatriates may often be viewed as paragons of professionalism and good practice in workplace behaviors. While the level of scrutiny from HCNs may be heightened for expatriates employed in 'local' organizations (Arp et al., 2013) like those of our sample, evidence that HCNs attentively observe and model expatriates' behaviors and dispositions may cause organizations to reconsider their expatriate selection, preparation, and performance management protocols.

We summarize the results of our analysis of HCNs' learning outcomes by directly linking our findings with the framework of informal and incidental learning that we use (Marsick and Watkins, 2001). Specifically, based on Vietnamese HCNs working with selfinitiated expatriates, our empirical findings collectively indicate the propositions that HCNs:

1. Develop primarily portable, soft capabilities rather than domain- or organizationspecific technical capabilities (learning outcomes);

2. Benefit most from a range of informal learning opportunities, including observations, collaborations and discussions, as well as adjustments they make to their own work approach in response to the expatriates' presence, rather than from structured developmental activities controlled by the expatriate (learning context); 
3. Make use of opportunities to observe expatriates in the workplace as an important means of professionalizing their own work practices (learning context);

4. Learn best when they have relationships with expatriates underscored by trust (learning context); and

5. Look for ways to curate their learning through intentionally positioning themselves in work and non-work situations that they believe are conducive to informal learning (learning context).

\section{Limitations and future research}

Before further elaborating the study's practical implications, several features of our research design that may limit the transferability of the results are of note. The first relates to the specific context of our field work. While the study's transferability benefits from a diverse sample of learning episodes (138) that unfolded in multiple organizations (13), organizational types (3), provincial regions (3), and professional contexts (6), the study's distinctive cultural context (i.e. Vietnamese nationals in organizations based in North and Central Vietnam) suggests caution in how the results might be transferred to different contexts. The absence of studies of informal learning within Vietnamese organizations makes attributing respondents' learning patterns to culturally-ingrained preferences problematic. Nonetheless, cultural values and attitudes that attach importance to interpersonal relationships (Meyer et al., 2006), personal development (Napier and Haong, 2013), and saving face (Borton, 2000), which are believed to be common in Vietnamese organizations, may have influenced the learning outcomes that respondents perceived as valued and how they approached developing these. By way of example, one explanation for the widespread use of vicarious learning may have been associated with overcoming stresses associated with cross-language interactions (Marschan et al., 1997; Neeley, 2013) that may have been particularly acute for Vietnamese respondents (Zhu et al., 2008). Similarly, respondents' preference for an insider mentor- 
protégé mode of learning may have related to Vietnamese comfort with in-group contact and/or concerns about cross-status communication (Borton, 2000). Further, even though Hunter (2010, p. 451) found evidence of intentional incidental learning among a very different sample - geographically-isolated sales agents working in the 'rapidly changing, competitive' Canadian pharmaceutical industry - respondents' culturally-ingrained learning attitudes may have made them more likely to instigate personal/professional development opportunities (Wang et al., 2005) and/or particular modes of learning (Tran, 2013). In a similar vein, other background characteristics of respondents (e.g. career stage or age relative to expatriates) may also have shaped their informal learning processes. Consequently, while the framework presented in Table 3 may be a useful template for studies exploring HCN learning in different cultural settings, the resultant spread of outcomes and contexts may differ to those that we report here.

Related to this, respondents' proficiency communicating with expatriates in a second language - primarily English - was an important enabler of many social and experiential learning opportunities reported in this study that would be unavailable to large numbers of HCNs in Vietnam and other host countries, whose proficiency in a shared language with expatriates may have been weaker. While our study was unable to collect valid indicators of respondents' or expatriates' proficiencies in a shared language, future studies examining the influence of language proficiency on the forms of informal intercultural learning are suggested (Yamazaki and Kayes, 2007).

Finally, the use of specific learning episodes to ground responses helped to overcome response biases such as selective recall or social desirability (Butterfield et al., 2005). Nonetheless, our study did not examine the extent to which the reported learnings were (a) utilized by respondents in their work, or (b) beneficial to respondents' work performance. While the distinction between personal and professional learning can be opaque (Candy and 
Matthews, 1998), the relatively large number of personal development outcomes that our study documents highlights the importance of future studies examining the transferability of these to respondents' work performance.

\section{Practical implications}

At a practical level, our findings contribute insights into how organizations might configure and manage expatriate placements in order to maximize HCNs' learning, and so improve the dividends accrued from the (the sizeable) investment of expatriate assignments with organizational development objectives. In particular, the learning hot-spots identified in Table 3 may provide a basis for configuring $\mathrm{HCN}$ /expatriate assignments and/or recruiting or preparing expatriates/HCNs in order to facilitate the development of particular learning outcomes for HCNs. For instance, our results suggest that opportunities to observe expatriates during day-to-day work practices is an especially potent way to help HCNs improve 'professionalism in work performance' and proficiency 'planning and organizing work'. Our results may also guide organizations' decisions about the best ways to achieve certain localization objectives, like specific types of mentoring that might be most helpful in developing particular HCN capabilities (Wong and Law, 1999). On this point, the very high rate of informal learning suggests a need to structure opportunities for HCNs to observe, consult, and/or work shadow expatriates, and for expatriates to be cognizant of role modelling positive workplace behaviors and attitudes. The results also hint at benefits from longer-term assignments that co-locate expatriates with HCNs allowing repeated observations and interactions, rather than short-term or more distant forms of expatriation (e.g. virtual assignments, business travelers). Through these insights, we give veracity and some explanatory texture to expatriate placements as effective mechanisms for conveying certain capabilities and dispositions associated with the performance of work. 
Our findings also reveal that many of the most valued learning outcomes of HCNs do not neatly fit into domain-specific capabilities. Most are context-neutral, unhinged from specific systems and processes within the host organization and so likely transferable across firm or sector. We suggest that this is partially attributable to the nature of these specific assignments, where expatriates were recruited external to the organization and primarily for their professional expertise rather than organizational knowledge. Nonetheless, it was clear that HCNs' learning portfolio was broader than just technical know-how. The relative scarcity of these 'higher order' capabilities in developing countries like Vietnam (World Bank, 2008) may, from a resource-based perspective, give them particular strategic potency. At the same time, their relative portability may limit their value for organizations intent on developing or retaining firm-specific capabilities. Our findings, therefore, foreshadow both the benefits and risks for organizations of this type of $\mathrm{HCN}$ development. For individual HCNs, on the other hand, our study unearths ways to develop career capital in an era when individuals are increasingly responsible for their professional development (Arthur and Rousseau, 1996).

\section{Conclusion}

Our empirical fieldwork has given voice to HCNs and, we believe, texture to the patterns of their learning experiences. In doing so, our study contributes to knowledge of the poorly understood dynamics of what and how expatriates support HCN learning, and so contributes to a more nuanced understanding of the vital but under-appreciated experiences of HCNs.

\section{REFERENCES}

Akin, G. (1987), "Varieties of managerial learning", Organizational Dynamics, Vol. 16 No. 2, pp. 36-48.

Andresen, M., Bergdolt, F., Margenfeld, J. and Dickmann, M. (2014), "Addressing international mobility confusion-developing definitions and differentiations for self- 
initiated and assigned expatriates as well as migrants", The International Journal of Human Resource Management, Vol. 25 No. 1, pp. 2295-2318.

Arp, F., Hutchings, K. and Smith, W.A. (2013), "Foreign executives in local organisations: An exploration of differences to other types of expatriates", Journal of Global Mobility, Vol. 1 No. 3, pp. 312-335.

Arthur, M.B. and Rousseau, D.M. (1996), The Boundaryless Career, Oxford University Press, Oxford.

Bandura, A. (1977), Social Learning Theory, Prentice-Hall, Englewood Cliffs, NJ.

Bell, P., Lewenstein, B., Shouse, A.W. and Feder, M.A. (2009), Learning Science in Informal Environments: People, places, and pursuits The National Academies Press, Washington, DC.

Billett, S. (2001), Learning in the Workplace: Strategies for effective practice, Allen \& Unwin, Crows Nest, NSW.

Black, J.S. and Mendenhall, M. (1991), "The U-curve adjustment hypothesis revisited: A review and theoretical framework", Journal of International Business Studies, Vol. 22 No. 2, pp. 225-247.

Bonache, J. and Brewster, C. (2001), "Knowledge transfer and the management of expatriation", Thunderbird International Business Review, Vol. 43 No. 1, pp. 145-168.

Borton, L. (2000), "Working in a Vietnamese voice", Academy of Management Perspectives, Vol. 14 No. 4, pp. 20-29.

Butterfield, L.D., Borgen, W.A., Amundson, N.E. and Maglio, A.-S.T. (2005), "Fifty years of the critical incident technique: 1954-2004 and beyond", Qualitative Research, Vol. 5 No. 4, pp. 475-497.

Caligiuri, P. and Bonache, J. (2016), "Evolving and enduring challenges in global mobility", Journal of World Business, Vol. 51 No. 1, pp. 127-141.

Candy, P. and Matthews, J. (1998), "Fusing learning and work: Changing conceptions of workplace learning". in D. Boud (Ed.), Current Issues and New Agendas in Workplace Learning, National Centre for Vocational Education Research, Leabrook, SA, pp. 1229.

Cheetham, G. and Chivers, G. (2001), "How Professionals Learn in Practice: An investigation of informal learning amongst people working in professions", Journal of European Industrial Training, Vol. 25 No. 5, pp. 246-292.

Chell, E. (1998), "Critical Incident Technique". in G. Symon and C. Cassell (Eds.), Qualitative Methods and Analysis in Organizational Research: A Practical Guide, Sage, London, pp. 51-72.

Eisenhardt, K.M., Graebner, M.E. and Sonenshein, S. (2016), "From the Editors - Grand challenges and inductive methods: Rigor without rigor mortis", Academy of Management Journal, Vol. 59 No. 4, pp. 1113-11123.

Enos, M.D., Kehrhahn, M.T. and Bell, A. (2003), "Informal learning and the transfer of learning: How managers develop proficiency", Human Resource Development Quarterly, Vol. 14 No. 4, pp. 369-387.

Eraut, M. (2004), "Informal learning in the workplace", Studies in Continuing Education, Vol. 26 No. 2, pp. 247-273. 
Euromonitor International. (2018a). "Business Dynamics: Vietnam", available at: https://www.portal.euromonitor.com (accessed 12 January, 2019)

Euromonitor International. (2018b). "Economy, Fiannce and Trade: Vietnam", available at: https://www.portal.euromonitor.com (accessed 12 January, 2019)

Evans, K., Hodkinson, P., Rainbird, H. and Unwin, L. (2006), Improving Workplace Learning, Routledge, New York.

Evans, P., Pucik, V. and Björkman, I. (2011), The Global Challenge: International Human Resource Management, 2nd edition, McGraw-Hill, New York.

Fee, A. and Gray, S.J. (2011), "Fast-tracking expatriate development: The unique learning environments of international volunteer placements", The International Journal of Human Resource Management, Vol. 22 No. 3, pp. 530-552.

Fee, A. and Gray, S.J. (2013), "Transformational learning experiences of international development volunteers in the Asia-Pacific: The case of a multinational NGO", Journal of World Business, Vol. 48 No. 2, pp. 196-208.

Flanagan, J.C. (1954), "The critical incident technique", Psychological Bulletin, Vol. 51 No. 4, pp. 327-358.

Froese, F.J., Peltokorpi, V. and Ko, K.A. (2012), "The influence of intercultural communication on cross-cultural adjustment and work attitudes: Foreign workers in South Korea", International Journal of Intercultural Relations, Vol. 36 No. 3, pp. 331-342.

Fryxell, G.E., Butler, J. and Choi, A. (2004), "Successful localization programs in China: An important element in strategy implementation", Journal of World Business, Vol. 39 No. 3, pp. 268-282.

Fuller, A. and Unwin, L. (2003), "Learning as apprentices in the contemporary UK workplace: Creating and managing expansive and restrictive participation", Journal of Education and Work, Vol. 16 No. 4, pp. 407-426.

Grant, R.M. (1996), "Toward a knowledge-based theory of the firm", Strategic Management Journal, Vol. 17 No. S2, pp. 109-122.

Guramatunhu-Mudiwa, P. and Angel, R.B. (2017), "Women mentoring in the academe: A faculty cross-racial and cross-cultural experience", Mentoring \& Tutoring: Partnership in Learning, Vol. 25 No. 1, pp. 97-118.

Heizmann, H., Fee, A. and Gray, S.J. (2018), "Intercultural knowledge sharing between expatriates and host-country nationals in Vietnam: A practice-based study of communicative relations and power dynamics", Journal of International Management, Vol. 24 No. 1, pp. 16-32.

Hezlett, S.A. (2005), "Protégés' learning in mentoring relationships: A review of the literature and an exploratory case study", Advances in Developing Human Resources, Vol. 7 No. 4, pp. 505-526.

Hocking, J.B., Brown, M. and Harzing, A.-W. (2007), "Balancing global and local strategic contexts: Expatriate knowledge transfer, applications, and learning within a transnational organization", Human Resource Management, Vol. 46 No. 4, pp. 513533. 
Hocking, J.B., Brown, M. and Harzing, A.W. (2004), "A knowledge transfer perspective of strategic assignment purposes and their path-dependent outcomes", The International Journal of Human Resource Management, Vol. 15 No. 3, pp. 565-586.

Hofstede, G. (2010), Cultures and Organizations: Software of the mind: Intercultural cooperation and its importance for survival, McGraw-Hill, New York.

Hong, J.F.L. and Snell, R.S. (2008), "Power inequality in cross-cultural learning: The case of Japanese transplants in China", Asia Pacific Business Review, Vol. 14 No. 2, pp. 253273.

Hunter, C. (2014), "Intentional incidental learning in the workplace: Implications for adult learning", New Horizons in Adult Education \& Human Resource Development, Vol. 26 No. 2, pp. 49-53.

Hunter, C.P. (2010), "Ways of learning in the pharmaceutical sales industry", Journal of Workplace Learning, Vol. 22 No. 7, pp. 451-462.

Illeris, K. (2002), Three Dimensions of Learning, Roskilde University Press/NIACE, Roskilde, Denmark and Leicester, UK.

Illeris, K. (2003), "Towards a contemporary and comprehensive theory of learning", International Journal of Lifelong Education, Vol. 22 No. 4, pp. 396-406.

Johnson, J.L. and Cullen, J.B. (2002), "Trust in cross-cultural relationships". in M.J. Gannon and K. Newman (Eds.), The Blackwell Handbook of Cross-cultural Management, Wiley-Blackwell, Oxford, UK, pp. 335-360.

Kolb, D. (1984), Experiential Learning: Experience as the Source of Learning and Development, Prentice-Hall, Englewood Cliffs, NJ.

Lane, H.W., Maznevski, M.L. and Mendenhall, M.E. (2004), "Globalization: Hercules meets Buddha". in H.W. Lane, M.L. Maznevski, M.E. Mendenhall and J. McNett (Eds.), The Blackwell Handbook of Global Management: A guide to managing complexity Blackwell Publishing Ltd, Oxford, pp. 3-25.

Lave, J. and Wenger, E. (1991), Situated Learning: Legitimate Peripheral Participation, Cambridge University Press, Cambridge.

Law, K.S., Song, L.J., Wong, C.-S. and Chen, D. (2009), "The antecedents and consequences of successful localization", Journal of International Business Studies, Vol. 40 No., pp. 1359-1373.

Law, K.S., Wong, C.S. and Wang, K.D. (2004), "An empirical test of the model on managing the localization of human resources in the People's Republic of China", The International Journal of Human Resource Management, Vol. 15 No. 4-5, pp. 635-648.

Leach, F. (1994), "Expatriates as agents of cross cultural transmission", Journal of Comparative Education, Vol. 24 No. 3, pp. 217-231.

Levin, D.Z. and Cross, R. (2004), "The strength of weak ties you can trust: The mediating role of trust in effective knowledge transfer", Management Science, Vol. 50 No. 11, pp. 1477-1490.

Liu, D., Liu, J., Kwan, H.K. and Mao, Y. (2009), "What can I gain as a mentor? The effect of mentoring on the job performance and social status of mentors in China", Journal of Occupational and Organizational Psychology, Vol. 82 No. 4, pp. 871-895. 
Manev, I.M. and Stevenson, W.B. (2001), "Nationality, cultural distance, and expatriate status: Effects on the managerial network in a multinational enterprise", Journal of International Business Studies, Vol. 32 No. 2, pp. 285-303.

Manuti, A., Pastore, S., Scardigno, A.F., Giancaspro, M.L. and Morciano, D. (2015), "Formal and informal learning in the workplace: A research review", International Journal of Training and Development, Vol. 19 No. 1, pp. 1-17.

Marschan, R., Welch, D. and Welch, L. (1997), "Language: The forgotten factor in multinational management", European Management Journal, Vol. 15 No. 5, pp. 591598.

Marsick, V.J., Volpe, M. and Watkins, K.E. (1999), "Theory and practice of informal learning in the knowledge era", Advances in Developing Human Resources, Vol. 1 No. 3, pp. $80-95$.

Marsick, V.J. and Watkins, K. (1990), Informal and Incidental Learning in the Workplace, Routledge, London and New York.

Marsick, V.J. and Watkins, K.E. (2001), "Informal and incidental learning", New Directions for Adult and Continuing Education, Vol. 89 No. Spring, pp. 25 - 34.

Marsick, V.J., Watkins, K.E., Scully-Russ, E. and Nicolaides, A. (2017), "Rethinking informal and incidental learning in terms of complexity and the social context", Journal of Adult Learning, Knowledge and Innovation, Vol. 1 No. 1, pp. 27-34.

Merriam, S.B., Caffarella, R.S. and Baumgartner, L.M. (2007), Learning in Adulthood: A Comprehensive Guide, 3rd edition, Jossey-Bass, San Francisco.

Meyer, K.E., Tran, Y.T.T. and Nguyen, H.V. (2006), "Doing business in Vietnam", Thunderbird International Business Review, Vol. 28 No. 2, pp. 263-290.

Minbaeva, D.B. and Michailova, S. (2004), "Knowledge transfer and expatriation in multinational corporations: The role of disseminative capacity", Employee Relations, Vol. 26 No. 6, pp. 663-679.

Napier, N.K. and Haong, V.Q. (2013), What We See, Why We Worry, Why We Hope: Vietnam Going Forward, Boise State University CCI Press, Boise, ID.

Neeley, T.B. (2013), "Language matters: Status loss and achieved status distinctions in global organizations", Organizational Science, Vol. 24 No. 2, pp. 476-497.

Petison, P. and Johri, L. (2008), "Managing local employees: Expatriate roles in a subsidiary", Management Decisions, Vol. 46 No. 5, pp. 743-760.

Ralston, D.A., Van Thang, N. and Napier, N.K. (1999), "A comparative study of the work values of North and South Vietnamese managers", Journal of International Business Studies, Vol. 30 No. 4, pp. 655-672.

Riusala, K. and Suutari, V. (2004), "International knowledge transfers through expatriation", Thunderbird International Business Review, Vol. 46 No. 6, pp. 743-770.

Robles, M.M. (2012), "Executive perceptions of the top 10 soft skills needed in today's workplace", Business Communication Quarterly, Vol. 75 No. 4, pp. 453-465.

Rubin, R.S. and Dierdorff, E.C. (2009), "How relevant is the MBA? Assessing the alignment of required curricula and required managerial competencies", Academy of Management Learning \& Education, Vol. 8 No. 2, pp. 208-224. 
Schürmann, E. and Beausaert, S. (2016), "What are drivers for informal learning?", European Journal of Training and Development, Vol. 40 No. 3, pp. 130-154.

Shao, J.J. and Al Ariss, A. (2020), "Knowledge transfer between self-initiated expatriates and their organizations: Research propositions for managing SIEs", International Business Review, Vol. 29 No. 1: 101634, pp. doi:https://doi.org/10.1016/j.ibusrev.2019.101634

Skule, S. (2004), "Learning Conditions at Work: A framework to understand and assess informal learning in the workplace", International Journal of Training and Development, Vol. 8 No. 1, pp. 8-20.

Szulanski, G. (1996), "Exploring internal stickiness: Impediments to the transfer of best practice within the firm", Strategic Management Journal, Vol. 17 No. S2, pp. 27-43.

Tennant, M. (1986), "An evaluation of Knowles' theory of adult learning", International Journal of Lifelong Education, Vol. 5 No. 2, pp. 113-122.

Toh, S.M., DeNisi, A.S. and Leonardelli, G.J. (2012), "The perspective of host country nationals in socializing expatriates: The importance of foreign-local relations". in C.R. Wanberg (Ed.), The Oxford Handbook of Organizational Socialization, Oxford University Press, Oxford, pp. 230-249.

Tran, T.T. (2013), "Is the learning approach of students from the Confucian heritage culture problematic?", Educational Research for Policy and Practice, Vol. 12 No. 1, pp. 5765.

Underhill, C.M. (2006), "The effectiveness of mentoring programs in corporate settings: A meta-analytical review of the literature", Journal of Vocational Behavior, Vol. 68 No. 2, pp. 292-307.

V. Nguyen, T. and F.L. Hong, J. (2013), "Local knowledge acquisition of foreign subsidiaries in Vietnam and China", Multinational Business Review, Vol. 21 No. 4, pp. 312-333.

Vaiman, V., Haslberger, A. and Vance, C.M. (2015), "Recognizing the important role of selfinitiated expatriates in effective global talent management", Human Resource Management Review, Vol. 25 No. 3, pp. 280-286.

van Bakel, M. (2019), "It takes two to tango: A review of the empirical research on expatriate-local interactions", The International Journal of Human Resource Management, Vol. 30 No. 21, pp. 2993-3025.

van Gelderen, M., van der Sluis, L. and Jansen, P. (2005), "Learning Opportunities and Learning Behaviours of Small Business Starters: Relations with goal achievement, skill development and satisfaction", Small Business Economics, Vol. 25 No. 1, pp. 97108.

Vance, C.M., Andersen, T., Vaiman, V. and Gale, J. (2014), "A taxonomy of potential contributions of the host country national local liaison role in global knowledge management", Thunderbird International Business Review, Vol. 56 No. 2, pp. 173191.

Vance, C.M., Vaiman, V. and Anderson, T. (2009), "The vital liaison role of host country nationals in MNC knowledge management", Human Resource Management, Vol. 48 No. 4, pp. 649-659.

Wang, J., Wang, G.G., Ruona, W.E.A. and Rojewski, J.W. (2005), "Confucian values and the implications for international HRD", Human Resource Development International, Vol. 8 No. 3, pp. 311-326. 
Watkins, K.E., Marsick, V.J., Wofford, M.G. and Ellinger, A.D. (2018), "The evolving Marsick and Watkins (1990) theory of informal and incidental learning", New Directions for Adult and Continuing Education, Vol. 2018 No. 159, pp. 21-36.

Whitmore, P.G. (1972a), The behavioral model as a tool for analyzing "soft skills". Paper presented at the CONARC Soft Skills Training Conference, Fort Bliss, TX, available at: https://apps.dtic.mil/dtic/tr/fulltext/u2/a099612.pdf (accessed 27 May, 2019).

Whitmore, P.G. (1972b), What are soft-skills? Paper presented at the CONARC Soft Skills Training Conference, Fort Bliss, TX, available at: https://apps.dtic.mil/dtic/tr/fulltext/u2/a099612.pdf (accessed 27 May, 2019).

Wong, C.S. and Law, K.S. (1999), "Managing localization of human resources in the PRC: A practical model", Journal of World Business, Vol. 34 No. 1, pp. 26-40.

World Bank. (2008). "Vietnam: Higher Education and Skills for Growth", World Bank Group, Washington, DC, available at: http://documents.worldbank.org/curated/en/439591468338403597/Vietnam-Highereducation-and-skills-for-growth (accessed 20 September, 2018)

Yamazaki, Y. and Kayes, D.C. (2007), "Expatriate learning: Exploring how Japanese managers adapt in the United States", International Journal of Human Resource Management, Vol. 18 No. 8, pp. 1373-1395.

Zhu, Y., Collins, N., Weber, M. and Benson, J. (2008), "New forms of ownership and human resource practices in Vietnam", Human Resource Management, Vol. 47 No. 1, pp. 157-176.

Zhu, Y. and Purnell, D. (2006), "Multinational NGOs and expatriation: A case study of a NGO in Vietnam", Asia Pacific Business Review, Vol. 12 No. 4, pp. 529-546. 
Table 1: List of research participants ${ }^{\mathrm{a}}$ by professional role and employer type

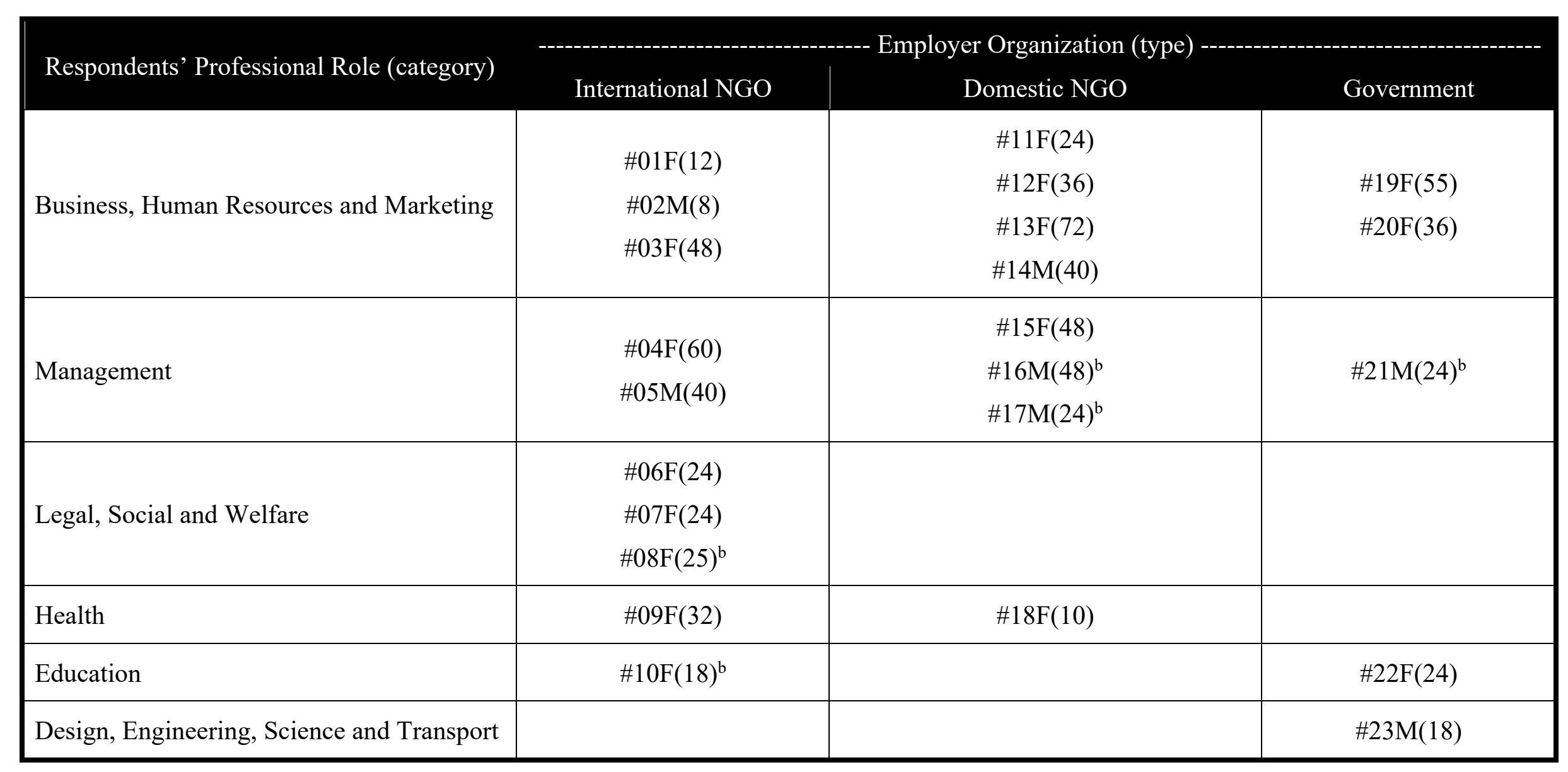

${ }^{a}$ Each respondent is represented in the table by her/his identifying code (\#01-23), gender (' $\mathrm{F}$ ' or ' $\mathrm{M}$ ') and the duration in months spent working with expatriates at the time of the interviews (in brackets).

${ }^{\mathrm{b}}$ Interviews that relied heavily on an interpreter. 
Table 2: Categories of learning episodes and learning processes distilled from empirical materials

\begin{tabular}{|c|c|c|}
\hline \multicolumn{2}{|r|}{ Category } & Operationalization \\
\hline \multirow{5}{*}{$\begin{array}{l}\text { Learning } \\
\text { outcomes }\end{array}$} & 1. Personal development & $\begin{array}{l}\text { Capabilities associated with respondents' personal development not related to a particular role or context but which contribute to work quality, including changed } \\
\text { outlook on aspects of work, increased commitment to work/project/profession, increased motivation, improved work attitude, improved flexibility, greater } \\
\text { resilience, and greater self-confidence in work performance. }\end{array}$ \\
\hline & $\begin{array}{l}\text { 2. Domain-specific } \\
\text { capabilities }\end{array}$ & $\begin{array}{l}\text { Capabilities specific to respondents' professional domain: (a) expanded technical knowledge or know-how, (b) improved performance of domain-related tasks } \\
\text { (e.g. more fluent performance), (c) more strategic outlook on profession or role, and (d) new domain-specific contacts/networks. }\end{array}$ \\
\hline & $\begin{array}{l}\text { 3. Role performance and } \\
\text { management } \\
\text { capabilities }\end{array}$ & $\begin{array}{l}\text { Capabilities required to manage people and projects and to perform work that are not specific to the professional domain. These include traits and behaviors } \\
\text { associated with 'professionalism' in terms of the work style and work ethic, as well as generic personal managerial skills like planning and organizing workloads } \\
\text { or projects, and managing deadlines. }\end{array}$ \\
\hline & $\begin{array}{l}\text { 4. Communication } \\
\text { capabilities }\end{array}$ & $\begin{array}{l}\text { Interpersonal communication abilities relating to improved English language skills (speaking/listening, and writing), or other communication-related outcomes } \\
\text { like producing messages (e.g. persuade/negotiate), receiving messages (listening), and relationship-building skills. }\end{array}$ \\
\hline & 5. Cultural capabilities & $\begin{array}{l}\text { Capabilities that improve the individual's cultural awareness (e.g. awareness of differences of perspectives stemming from one's culture) or enhance cross- } \\
\text { cultural competence. We distinguish between culture-specific capabilities (e.g. knowledge of expatriates' cultural practices), and culture-general capabilities (e.g. } \\
\text { understanding the influence of cultural patterns more broadly). }\end{array}$ \\
\hline \multirow{6}{*}{$\begin{array}{l}\text { Learning } \\
\text { contexts }\end{array}$} & 6. Observing & $\begin{array}{l}\text { Observing expatriates performing work. Includes structured modelling of particular behaviors (e.g. demonstrating a practice for the purpose of HCN learning), } \\
\text { or unstructured role-modelling (i.e. HCNs observing expatriates' work or other interactions without the expatriates' explicit awareness). }\end{array}$ \\
\hline & 7. Collaborating & $\begin{array}{l}\text { Collaborating with expatriates on projects and managing peer-to-peer relationships associated with these. Four nodes in this category include HCNs and } \\
\text { expatriates working jointly on shared tasks, HCNs supporting expatriates with their individual workloads and vice versa, and HCNs resolving process-related } \\
\text { difficulties during collaborations with expatriates. }\end{array}$ \\
\hline & 8. Adjusting & $\begin{array}{l}\text { HCNs needing to adjust as a result of expatriates' presence via (a) recognizing and responding to differences ('cultural differences'), (b) communicating in } \\
\text { unfamiliar ways ('communicating differently'), or (c) performing unfamiliar or more challenging work role/s ('new role'). }\end{array}$ \\
\hline & 9. Discussing & $\begin{array}{l}\text { Discussing issues and ideas with expatriates, including unstructured conversations that occurred outside the workplace (e.g. lunch breaks), discussing specific } \\
\text { features of a shared activity or project, and in structured periodic or ad-hoc meetings with expatriates (e.g. weekly reviews). }\end{array}$ \\
\hline & 10. Consulting & $\begin{array}{l}\text { Consulting with expatriates to seek advice or feedback; receiving explicit feedback formally (e.g. structured feedback session) or informally (e.g. expatriate } \\
\text { correcting a mistake), as well as HCNs instigating consultation with expatriates, typically via informal requests for advice. }\end{array}$ \\
\hline & 11. Training & $\begin{array}{l}\text { Participating in structured training exchanges with expatriates. This comprises workshops, presentations and other 'structured' training programs delivered by } \\
\text { expatriates, one-to-one tutorials with expatriates, as well as lessons conducted by expatriates on an ad-hoc basis, falling outside the expatriates' designated roles } \\
\text { (e.g. semi-formal English language 'classes' after work hours). }\end{array}$ \\
\hline
\end{tabular}


Table 3 (Panel I): Overview of host-country national learning episodes (learning outcomes and learning contexts)

\begin{tabular}{|c|c|c|c|c|c|c|c|c|c|c|c|c|c|}
\hline \multirow[b]{2}{*}{ Learning outcomes } & \multirow{2}{*}{$\begin{array}{c}\% \text { sample } \\
(\mathrm{n}=23)\end{array}$} & \multicolumn{3}{|c|}{-------- 6. Observing --------- } & \multicolumn{5}{|c|}{ 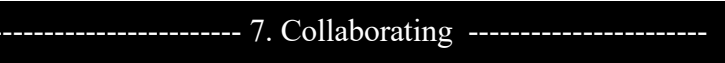 } & \multicolumn{4}{|c|}{---------------- 8 8. Adjusting ----------------' } \\
\hline & & 6.1 & 6.2 & Sub-total & 7.1 & 7.2 & 7.3 & 7.4 & Sub-total & 8.1 & 8.2 & 8.3 & Sub-total \\
\hline 1. Personal development & $96 \%$ & 7 & 1 & 8 & $\mathbf{0}$ & $\mathbf{0}$ & $\mathbf{0}$ & 5 & 5 & 10 & 4 & 1 & 15 \\
\hline 1.1 Changed outlook & $43 \%$ & 1 & - & 1 & - & - & - & 2 & 2 & 1 & 1 & - & 2 \\
\hline 1.2 Openness to different points of view & $39 \%$ & 1 & - & 1 & - & - & - & 2 & 2 & 3 & 2 & - & 5 \\
\hline 1.3 Overall self-confidence & $30 \%$ & - & - & 0 & - & - & - & 1 & 1 & 1 & - & 1 & 2 \\
\hline 1.4 Flexibility/adaptability & $22 \%$ & 1 & 1 & 2 & - & - & - & - & 0 & 2 & 1 & - & 3 \\
\hline 1.5 Inspiration from commitment, motivation and attitude & $17 \%$ & 2 & - & 2 & - & - & - & - & 0 & 2 & - & - & 2 \\
\hline 1.6 Resilience and persistence, including patience & $9 \%$ & 1 & - & 1 & - & - & - & - & 0 & 1 & - & - & 1 \\
\hline 1.7 Work-life balance & $4 \%$ & 1 & - & 1 & - & - & - & - & 0 & - & - & - & 0 \\
\hline 2. Domain-specific capabilities & $100 \%$ & 4 & 4 & 8 & 3 & 1 & $\mathbf{0}$ & $\mathbf{0}$ & 4 & 1 & 1 & 2 & 4 \\
\hline 2.1 Technical knowledge/know-how & $91 \%$ & 2 & 1 & 3 & 2 & 1 & - & - & 3 & 1 & - & 2 & 3 \\
\hline 2.2 Task performance (e.g. improved fluency) & $35 \%$ & 2 & 2 & 4 & 1 & - & - & - & 1 & - & - & - & 0 \\
\hline 2.3 Strategic outlook on profession/role & $13 \%$ & - & 1 & 1 & - & - & - & - & 0 & - & 1 & - & 1 \\
\hline 2.4 Develop domain-specific contacts & $4 \%$ & - & - & 0 & - & - & - & - & 0 & - & - & - & 0 \\
\hline 3. Role performance and management capabilities & $100 \%$ & 14 & 1 & 15 & 5 & o & 1 & $\mathbf{0}$ & 6 & $\mathbf{0}$ & $\mathbf{0}$ & $\mathbf{0}$ & $\mathbf{0}$ \\
\hline 3.1 Professionalism in work performance (work style and ethic) & $61 \%$ & 9 & - & 9 & 1 & - & 1 & - & 2 & - & - & - & 0 \\
\hline 3.2 Planning and organizing work & $35 \%$ & 4 & - & 4 & 3 & - & - & - & 3 & - & - & - & 0 \\
\hline 3.3 Punctuality, managing deadlines & $13 \%$ & 1 & 1 & 2 & 1 & - & - & - & 1 & - & - & - & 0 \\
\hline 4. Communication capabilities & $78 \%$ & 6 & o & 6 & 5 & 3 & $\mathbf{0}$ & $\mathbf{0}$ & 8 & o & 5 & 1 & 6 \\
\hline 4.1 English language skills (speaking/listening) & $35 \%$ & - & - & 0 & 2 & - & - & - & 2 & - & 1 & 1 & 2 \\
\hline 4.2 English language skills (writing) & $22 \%$ & 1 & - & 1 & 1 & 2 & - & - & 3 & - & 1 & - & 1 \\
\hline 4.3 Message production (e.g. persuasion, flexibility, negotiating) & $35 \%$ & 4 & - & 4 & 1 & 1 & - & - & 2 & - & 2 & - & 2 \\
\hline 4.4 Managing social and work interactions, relationship building & $13 \%$ & 1 & - & 1 & 1 & - & - & - & 1 & - & - & - & 0 \\
\hline 4.5 Message reception (e.g. listening, inferring meaning) & $9 \%$ & - & - & 0 & - & - & - & - & 0 & - & 1 & - & 1 \\
\hline 5. Cultural capabilities & $30 \%$ & 1 & $\mathbf{0}$ & 1 & 3 & $\mathbf{0}$ & $\mathbf{0}$ & $\mathbf{0}$ & 3 & 2 & 0 & $\mathbf{0}$ & 2 \\
\hline 5.1 Culture-specific skills and understanding & $17 \%$ & - & - & 0 & 2 & - & - & - & 2 & - & - & - & 0 \\
\hline 5.2 Culture-general skills and understanding & $17 \%$ & 1 & - & 1 & 1 & - & - & - & 1 & 2 & - & - & 2 \\
\hline Total & & 32 & 6 & 38 & 16 & 4 & 1 & 5 & 26 & 13 & 10 & 4 & 27 \\
\hline
\end{tabular}

${ }^{\mathrm{a}}$ Indicates a learning context involving formal learning.

${ }^{\mathrm{b}}$ Indicates an informal learning context where learning was the primary objective. 
Table 3 (Panel II): Overview of host-country national learning episodes (learning outcomes and learning contexts)

\begin{tabular}{|c|c|c|c|c|c|c|c|c|c|c|c|c|c|}
\hline \multirow[b]{2}{*}{ Learning outcomes } & \multicolumn{4}{|c|}{ 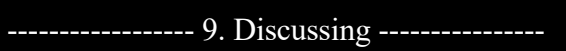 } & \multicolumn{4}{|c|}{--------------- 10. Consulting ------------- } & \multicolumn{4}{|c|}{ 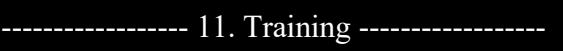 } & \multirow{2}{*}{ Total } \\
\hline & 9.1 & 9.2 & 9.3 & Sub-total & 10.1 & 10.2 & 10.3 & Sub-total & 11.1 & 11.2 & 11.3 & Sub-total & \\
\hline 1. Personal development & 2 & 2 & 1 & 5 & 4 & 2 & 0 & 6 & 2 & 0 & 0 & 2 & 41 \\
\hline 1.1 Changed outlook & 2 & 1 & 1 & 4 & 3 & 1 & - & 4 & - & - & - & 0 & 13 \\
\hline 1.2 Openness to different points of view & - & - & - & 0 & - & 1 & - & 1 & - & - & - & 0 & 9 \\
\hline 1.3 Overall self-confidence & - & 1 & - & 1 & 1 & - & - & 1 & 2 & - & - & 2 & 7 \\
\hline 1.4 Flexibility/adaptability & - & - & - & 0 & - & - & - & 0 & - & - & - & 0 & 5 \\
\hline 1.5 Inspiration from commitment, motivation and attitude & - & - & - & 0 & - & - & - & 0 & - & - & - & 0 & 4 \\
\hline 1.6 Resilience and persistence, including patience & - & - & - & 0 & - & - & - & 0 & - & - & - & 0 & 2 \\
\hline 1.7 Work-life balance & - & - & - & 0 & - & - & - & 0 & - & - & - & 0 & 1 \\
\hline 2. Domain-specific capabilities & 1 & 4 & 1 & 6 & 5 & 2 & 3 & 10 & 1 & 2 & 0 & 3 & 35 \\
\hline 2.1 Technical knowledge/know-how & 1 & 3 & 1 & 5 & 3 & 2 & 1 & 6 & 1 & 2 & - & 3 & 23 \\
\hline 2.2 Task performance (e.g. improved fluency) & - & - & - & 0 & 1 & - & 2 & 3 & - & - & - & 0 & 8 \\
\hline 2.3 Strategic outlook on profession/role & - & 1 & - & 1 & - & - & - & 0 & - & - & - & 0 & 3 \\
\hline 2.4 Develop domain-specific contacts & - & - & - & 0 & 1 & - & - & 1 & - & - & - & 0 & 1 \\
\hline 3. Role performance and management capabilities & 3 & 1 & 0 & 4 & 1 & 1 & 0 & 2 & 0 & 0 & 0 & 0 & 27 \\
\hline 3.1 Professionalism in work performance (work style and ethic) & 2 & - & - & 2 & 1 & 1 & - & 2 & - & - & - & 0 & 15 \\
\hline 3.2 Planning and organizing work & 1 & 1 & - & 2 & - & - & - & 0 & - & - & - & 0 & 9 \\
\hline 3.3 Punctuality, managing deadlines & - & - & - & 0 & - & - & - & 0 & - & - & - & 0 & 3 \\
\hline 4. Communication capabilities & 1 & 1 & 1 & 3 & 0 & 3 & 0 & 3 & 0 & 0 & 1 & 1 & 27 \\
\hline 4.1 English language skills (speaking/listening) & 1 & - & - & 1 & - & 2 & - & 2 & - & - & 1 & 1 & 8 \\
\hline 4.2 English language skills (writing) & - & - & - & 0 & - & - & - & 0 & - & - & - & 0 & 5 \\
\hline 4.3 Message production (e.g. persuasion, flexibility, negotiating) & - & - & 1 & 1 & - & - & - & 0 & - & - & - & 0 & 9 \\
\hline 4.4 Managing social and work interactions, relationship building & - & - & - & 0 & - & 1 & - & 1 & - & - & - & 0 & 3 \\
\hline 4.5 Message reception (e.g. listening, inferring meaning) & - & 1 & - & 1 & - & - & - & 0 & - & - & - & 0 & 2 \\
\hline 5. Cultural capabilities & 1 & 0 & 0 & 1 & 0 & 0 & 0 & 0 & 0 & 0 & 1 & 1 & 8 \\
\hline 5.1 Culture-specific skills and understanding & 1 & - & - & 1 & - & - & - & 0 & - & - & 1 & 1 & 4 \\
\hline 5.2 Culture-general skills and understanding & - & - & - & 0 & - & - & - & 0 & - & - & - & 0 & 4 \\
\hline Total & 8 & 8 & 3 & 19 & 10 & 8 & 3 & 21 & 3 & 2 & 2 & 7 & 138 \\
\hline
\end{tabular}

${ }^{\mathrm{a}}$ Indicates a learning context involving formal learning.

${ }^{\mathrm{b}}$ Indicates an informal learning context where learning was the primary objective. 